Alicante Journal of English Studies / Revista Alicantina de Estudios Ingleses

ISSN: 0214-4808 | e-ISSN: 2171-861X

Special Issue: Theatre and Performance Studies in English

No. 35, 2021, pages 75-97

https://doi.org/10.14198/raei.2021.35.04

\title{
Disrupting Temporalities, Multiplying the Self: An Age-Studies Approach to Two Contemporary Plays
}

\author{
Núria Casado-Gual \& Inesa Shevchenko-Hotsuliak
}

\begin{abstract}
Authors:
Núria Casado-Gual

Universitat de Lleida, Spain

nuria.casado@udl.cat

https://orcid.org/0000-0002-3778-6284

Inesa Shevchenko-Hotsuliak

Universitat de Lleida, Spain

inesa.shevchenko@udl.cat

https://orcid.org/0000-0002-4834-2320

Date of reception: 27/02/2021

Date of acceptance: $21 / 06 / 2021$

Citation:

Casado-Gual, Núria and Inesa Shevchenko-Hotsuliak. 2021. "Disrupting Temporalities, Multiplying the Self: An Age-Studies Approach to Two Contemporary Plays." Alicante Journal of English Studies 35: 75-97.

https://doi.org/10.14198/raei.2021.35.04

(C) 2021 Núria Casado-Gual \& Inesa

Shevchenko-Hotsuliak

Licence: This work is licensed under a Creative Commons Attribution 4.0 International License (CC BY 4.0)

\section{(C) (1)}

\begin{abstract}
:
In our increasingly aged societies, old age continues to be equated with decline (Gullette 2004) and becomes the source of the most invisible yet persistent forms of discrimination, namely, ageism (Butler 1969). Even though theatre, like other artistic forms, has traditionally promoted a negative image of ageing (Mangan 2013), some contemporary plays have begun to favour more complex portrayals of old age. Nevertheless, when considered from a gender-based angle, these portrayals often acquire quite a problematic undertone: while roles for older female actors remain exceptional, many peripheral or, if centred, mainly problematic dramatizations of ageing femininity in the theatre arena fuel age prejudice against older women on and off stage. This article offers an age-focused analysis of two plays that counteract stereotypical images of female ageing through various dramaturgical strategies: Michel Tremblay's Albertine in Five Times (1984) and Matt Hartley's Here I Belong (2016). Through a comparative analysis of the Naturalistic and Non-Naturalistic devices employed in the two plays, and the examination of the meanings of age generated by the characterization of the two female protagonists, we hope to demonstrate that Tremblay's and Hartley's texts contribute to creating a truly anti-ageist theatre while at the same time enhancing the visibility of the older woman on the stage.
\end{abstract}

Keywords: modern drama; ageing studies; cultural gerontology; gender; drama criticism 


\section{Introduction: Ageing Studies, Theatre and Contemporary Drama}

Ever since classical authors like William Shakespeare or Calderón de la Barca established the trope of 'the theatre of the world' in the Renaissance, and seminal sociologists like Erving Goffman (1956) or philosophers like Judith Butler (1990, 1993) recognized the 'performative elements' that help explain aspects of our socially- and culturally-constructed identities, theatre has been regarded as an ideal domain through which human behaviour and society in general can be interpreted and understood. By giving visibility to certain topics in such a complex way, theatre artists inevitably reinforce, undermine or even help transform the discourses that shape them. Among many of the challenges affecting our world, ageing is, indeed, one of the main preoccupations of our contemporary society. Contrary to its alleged universality as a biological process, the experience of ageing is a multifaceted phenomenon in which social and cultural factors play a central role. Consequently, the representation of old age on the stage is also highly conditioned by the socio-cultural background of the ageing figures, in which gender difference is paramount. As observed by the pioneering age scholar Margaret Morganroth Gullette, women are "still aged by culture younger than men are" $(2004,23)$. The theatre world mirrors the double alienation that older women undergo in our youth-obsessed, patriarchal societies, by either rendering them gradually invisible on the stage, or giving them predominantly marginal roles. Resorting to the increasingly intersecting frameworks of theatre, ageing and gender studies, this article draws attention to the dramatic representation of ageing, and of older women in particular, in two contemporary plays that offer a more complex portrayal of female old age: namely, Michel Tremblay's Albertine in Five Times (1984) and Matt Hartley's Here I Belong (2016). This study concurrently invites to develop further research in contemporary theatre through the lens of ageing studies. While integrating a critical examination of old age (and its intersection with gender) into theatre criticism enriches the analysis of modern drama with a highly significant contemporary perspective, providing more visibility to alternative portrayals of female old age on the stage contributes to dismantling reductive perceptions of later life and femininity.

Old age has been part of the history of theatre from its beginnings: in the Western world, the iconic figure of Oedipus, which Sophocles recreated as an old man in Oedipus at Colonus was, after all, one of the main sources of inspiration for Shakespeare's emblematic tragedy of ageing: The Tragedy of King Lear. However, it is not until quite relatively recently that the topic of ageing has started to re-emerge in contemporary drama from a modern perspective. In the so-called advanced societies of the Western world, the ageing demographic is regarded as both a sign of 
progress and, at the same time, a source of individual and collective concern. The contradiction of the so-called "longevity revolution," as Robert Butler has named it (2008), lies in the refusal to celebrate the extension of our later years as a scientific and social triumph, and to accept old age as a valuable stage of life. Instead, our aged societies cling to youth as a core value (Woodward 1991; Gullette 2004), deny the inevitable reality of death (Elias 1985), and consider older people as a social burden (Butler 2008, 40), while at the same time condemning them to a subaltern position whereby they are homogenized and denied agency or even visibility (Gullette 2011). This marginalization is a manifestation of the general social anxiety towards ageing itself. It is also the cause of what Butler (1969) coined as "ageism," that is, prejudice towards people due to their age.

In her insightful book Aged by Culture (2004), Gullette invites the academia to move beyond the boundaries of disciplinarity through the consideration of age from the social sciences and the humanities, with key concepts in common such as those of "cultural age" or "age as a narrative." Other age scholars have encouraged the same disciplines to generate a fruitful dialogue among their perspectives and methods (Swinnen and Port 2012). Instigated by the defiance to accept decline as the dominant element of old age, ageing studies foregrounds the "inside of ageing": as Stephen Katz contends in a foundational article, this interdisciplinary field pursues to answer the eternal question of what the process of growing old really means $(2014,20)$. Valerie Barnes Lipscomb, one of the initiators of the intersection between ageing and theatre studies, has argued that theatre is a perfect domain to explore and theorise about age from at least one of these three main perspectives: "the performative on stage, the narrative in the script and the critical questioning of ageism and chronological/biological age in the multiple realities of performance" $(2012,118)$. Other age-focused approaches to theatre and performance that started the field (Basting 1998; Lipscomb and Marshall 2010; Fuchs 2014) have developed more recently into monographic analyses, with relevant contributions to dramaturgical analysis (Goldman and Switzky 2016; Lipscomb 2016b; Bronk 2017; Henderson 2016), senior performance and/ or applied theatre (Basting 1998; Bernard and Munro 2015; McCormick 2017; Gillespie and Rowen 2020), or specific analyses of productions (Mangan 2013; Moore 2014), to name a few. Much of this scholarship stimulates a shift from ageist and stereotypical images of old age, as have been traditionally promoted on stage (Mangan 2013, 23), towards some alternatives to the "authoritative narrative[s]" of decline (Gullette 2004, 13) that dominate contemporary ideologies on ageing.

Gender has also played a significant role in quite a few of the approaches that theatre scholars have taken towards age. In fact, the importance of gender is not a novelty in the fields of ageing and theatre studies: "gender," as Gullette has put it, "always has an age too" $(2004,160)$. Even taking this connection further, 
quite a few influential ageing scholars, like Kathleen Woodward, contend that ageing is a truly "feminist issue" (2006, 181), not only because women dominate the ageing demographic (Peace et al. 2007, 4-5), but also because this complex process, as significant as any other stage of life, is "treated in terms of being weak, dependent, passive-and thus de-valued"; in other words, all too often ageing is feminized (Wehrle 2020, 77). The way women see themselves represented, and hear themselves discussed in the theatre (and, likewise, in films, TV series and other cultural texts with a direct social impact) may determine the way they can envisage, perceive, experience or perform their own old age in their lives (Byrski 2014, 17); in other words, these representations generate specific "age effects" in them, as Bridie Moore, drawing from Butler, contends $(2014,164)$.

Departing from the composite framework of theatre and age studies, also in its intersections with gender, this article aims at examining current conceptualizations of ageing and old age through the study of two modern plays. In the light of notions central to ageing studies, such as the narrative of decline, age-related stereotypes, the social and psychological dimensions of age, the life review, young/old and carer/cared binaries, and derived concepts such as 'age effects', our analysis intends to show that, by depicting lives of women who either 'age' on stage or interact with their multiple selves, Tremblay's and Hartley's scripts and their resulting shows provide the reader with the possibility of disrupting stereotyped notions of female ageing. Through an age-centred examination of the various dramaturgical conventions used in the two texts, in which both Naturalistic and Non-Naturalistic or Brechtian devices are observed, the article explores the ways in which Albertine in Five Times and Here I Belong undermine the prevalent view of old age as a separate life stage predominantly defined by loss, while at the same time staging different (sometimes contradictory) cultural constructions of female ageing, all of which enhance the complexity and diversity of the experience of growing older from a gender perspective. As will be shown, whereas Aristotelian dramatic structures and Naturalistic strategies of characterization ground the portrayals of the two older characters firmly within their respective socio-cultural contexts and generate empathic 'age effects' in readers and audience members, the Non-Aristotelian approaches or NonNaturalistic/epic conventions utilized in the two playscripts aim, à la Brecht, at a distanced, and, therefore, more critical representation of the process of growing older as a woman in all its complexity. Ultimately, the study considers how, through the combination of Aristotelian and Non-Aristotelian structures, and Naturalistic and Non-Naturalistic resources in the two plays, as well as their respective and complementary 'age effects,' Tremblay's and Hartley's plays contribute to paving the way for a truly anti-ageist theatre in which older women are endowed with rich characterizations in lead roles. 


\section{Stages of Ageing: Matt Hartley's Here I Belong}

Here I Belong is a four-act play that the British author Matt Hartley wrote on commission for the UK-based rural-theatre company Pentabus. The show premiered at Bromfield Village Hall, Shropshire in 2016, and received about fifty performances in two different tours between 2016 and 2018. ${ }^{1}$ Initially devised as a two-hander, Here I Belong certainly allows for a small-production format that can easily be transferred and adapted to all kinds of theatre spaces and community halls. In fact, a village hall is the play's only presentational space, which signals rural life as one of the central themes of the piece. At the same time, the plot focuses on one of the community members over six decades of her life, which renders female ageing one of the most salient aspects of the text. Our age-focused examination of Hartley's piece highlights the following aspects: the structure of the play and its connections with different discourses of ageing; the importance that 'age' plays in the protagonist's characterization; and, finally, the potential "age effects" that the emotional responses embedded in the text may have on its readers and audiences.

From various complementary perspectives, ranging from social (Bytheway 2011; Hepworth 2000; Katz 2005) through cultural (Gullette 2004; Gullette 2017; Woodward 1991; Dolan 2012; Worsfold 2011), historical (Cole et al. 2010) or narrative (Hartung et al. 2009; Randall and McKim 2008; Kenyon et al. 1999) angles, age critics have noted the powerful impact that stories and re-tellings of ageing may have in prevailing conceptualizations of age. At a dramaturgical level, Elinor Fuchs contends that traditional forms of drama, based on the Aristotelian model, tend to favour a structure of 'peak-and-decline' that runs in parallel to the sociocultural perception of ageing as a period of decadence and loss (2016). In contrast to this pattern, Non-Aristotelian or epic structures have the capacity to imagine alternative conceptualizations of old age. Here I Belong straddles between these two dramaturgical poles: on the one hand, its four-act structure, with a lapse of about twenty years or more between each of the acts, generates an epic representation of Elsie's life that stresses four particular moments. Through it, an open representation of her process of ageing is offered, where each episode has its own entity and, as in a Brechtian piece, Elsie's personality and personal story are signified as resulting from the accumulation of various kinds of circumstances, including historical events that frame turning points in her life (like the coronation of Queen Elizabeth, or the onset of Margaret Thatcher's era). On the other hand, the presentation of the four acts in chronological order generates the illusion

1 Information taken from the section devoted to this production on Pentabus' website (https://pentabus.co.uk/index.php/here-i-belong) 
of a 'unified' character within a cohesive life story, so even if the unity of time is disrupted, the sequential presentation of the character's biography provides unity to the action, as well as the illusion of a narrative arc whereby the character is constructed and understood. The superimposition of epic and Aristotelian structures in the piece leads to a composite narrative effect with regard to the play's representation of ageing: whilst the epic pattern enables the possibility of knowing and re-interpreting Elsie through different age-identities, the play's compliance with the principle of succession in its dramatization of time offers, instead, a representation of her ageing process as mainly submitted to the laws of biology and to heteronormative sociocultural conventions. These, at the same time, tend to evoke the narrative of decline. Hence, the references to loss and death (actual or imagined, of others, or Elsie's) increase as of Act III, in the same way that Elsie is gradually depicted as less connected with the new ways of life epitomized by the younger figures. For example, in the last Act she appears to be the last member of the community to maintain certain traditions, such as reading the Radio Times (100), and the absence of younger people in the village is depicted as a problem $(96,99,100,103)$.

The analysis of Elsie's character creation leads to a similar contrast of agebased connotations. Starting with the presentation of 'four ages' in Hartley's NonAristotelian, epic rendering of the character, one could say that each of them leads to 'four different performances of age.' Despite the relative value of age-categorizations as segregated life stages, these can be identified as 'late youth' (represented by Elsie in Act I, when she is twenty-seven), 'late middle-age' (symbolized by Elsie at the age of fifty-three, in Act II), 'old age' (in Act III, when Elsie is seventy-two) and 'old old' age or 'fourth age' (which shows Elsie on her ninetieth birthday). In general terms, the 'four ages' through which Elsie is depicted conform to traditional/heteronormative views of the life stages they refer to, with recognizable turning points that connect each of the four moments, and several aspects of characterization that signify different aspects of the 'age construct.' For example, in Act I, twenty-seven-year-old Elsie is presented as a hard-working, vital woman, pregnant with her daughter and active in the community, and full of hopes for the future, at both personal and communal levels, as well as plagued with insecurities as the 'stranger' from London who has married into the village. In Act II, the fiftythree-year-old version of the same character shows her as a strong woman who starts to display minor signs of physical ageing, like the loss of sight; and as a confident and important member of the community, who becomes an improvised mentor for her best friend's daughter, Marion, while she adjusts to her own 'empty nest' at home. The same conventional and, yet, multi-faceted depictions of 'age' are detected in Act III, when at seventy-two Elsie is presented as a less dynamic and more poised character, aware of the changes the village has undergone, and coping 
with the death of her husband, while at the same time retaining a dignified attitude on his funeral day. In Act IV, Elsie's 'old old' age is visibly constructed through the character's more noticeable physical and cognitive fragility; and complemented, at a symbolic level, by her isolation as a member of her age group in the village and, emotionally speaking, by her puzzlement at having reached an age she would have never thought she would get to be.

As the examples aforementioned demonstrate, Hartley resorts to a realistic combination of biological and social aspects of age in order to recreate Elsie's journey through her life course. Coherent with the Aristotelian/Naturalistic conception of the character as a unity, he associates Elsie's biological and sociocultural circumstances with particular psychological effects, hence offering a portrayal of female ageing that conforms to normative scripts of age and gender. Thus, in each of the four acts, Elsie behaves as the 'average woman of her age' by complying with traditional scripts of age and gender that intersect, also in predictable ways, with her other markers of identity. By stressing her personal development as a heterosexual, working-class Londoner who enters her small community as "the outsider" (12) and ends up regarded as the village's "Queen" (89), the playwright enhances the symbolic value that Elsie's process of ageing has at a communal level.

However, Here I Belong is also innovative "agewise"-to borrow from Gullette's pun (2011)—in that it focuses on life stages where the process of ageing becomes more self-conscious for its female protagonist. More significantly, it devotes two of the four acts of the play to the representation of old agefairly uncommon feature in contemporary drama, especially if we consider the prevailing invisibility "or disturbing absence," as Moore puts it, of the so-called 'fourth age' on the stage $(2018,15)$. Thus, the youngest of the four 'Elsies' is in fact about to enter a life stage in which, as a mother, she will become particularly aware of her own age and her mortality (Kuchner and Porcino 1988, 274-275); and especially as of Act II, which coincides with an important turning point for female ageing that is often identified with the menopausal years (Greer 1992), most of the play enhances Elsie's various transitions into later life as a grown, older, or 'old old' woman. It is relevant to note that the categories 'older' and 'old' are not signalled as 'final stages' in the play, but as distinctive and constituent parts of a continuum in which different categories of 'agedness' can be distinguished. In this way, the play's presentation of late youth as a starting point (instead of as an ending, as typical of youth-centred narratives) and, more significantly, of young old age as another transitional phase full of potential, instead of as a pathologized transition due to menopause (King 2013, 134) or a simplified culmination, reinforces the many transformations that its protagonist undergoes in her allegedly 'settled' adulthood. In the same vein, choosing to close the play 
with Elsie's making a wish over her ninetieth birthday cake enhances the play's celebration of 'old old' age; but, above all, it reinforces the dynamic presentation of all ages as thresholds of future actions.

The representation of midlife-ageing into old-old age as a constant process of 'becoming' leads to an anti-ageist theatrical narrative: not only does it underline the dynamic nature of age throughout the life course, but it also reinforces the human capacity to change and/or adjust to changes at all ages. At the same time, the play also constructs the gendered component of ageing in a similar way: Elsie's process of continuous transformation also entails a perpetual re-construction of her own womanhood, one in which femininity remains subject to constant readjustments at personal and public levels, and for which 'age' is an important conditioning factor (Cruikshank 2009; Friedan 2001; Macdonald and Rich 2001). In this sense, Hartley's contrasting Elsie with another character who is always in her twenties in each of the four acts helps visualize the diverse forms of femininity that result from the combination of age and gender: while Marion, Scarlett and Katie, Elsie's counterparts in Acts II, III and IV, always remain dynamic, vital, and yet full of insecurities, very much like Elsie herself in Act One, the 'older Elsies' gradually become more fragile throughout the play and less in touch with new fashions and trends, but grow in self-determination, courage, and wisdom as the play advances, all of which enables them to mentor their younger partners.

Beyond the sociocultural meanings derived from Elsie's characterization as an adult/older woman, and closely connected with the strong psychological basis of the character, it is also possible to consider her subjective or personal age, to use Woodward's categorization $(1991,149)$. It is through this particularized dimension, which expresses how the character 'feels' about her age, that Hartley also undermines scripts of 'age and gender.' This becomes especially evident in Act III, when despite feeling deeply about the loss of her husband, Elsie is also capable of imagining her later years as a period full of possibilities: as she tells Scarlett, the young girl she accidentally meets before the memorial for her late husband: "We weren't joined at the hip. I'll find things or even more things if those things aren't enough" (78). Elsie's pro-active attitude in front of an essential loss is developed further in Act IV when the presence of her ten photo albums reveals that she went travelling around the world when she was in her eighties. This information certainly undermines the stereotypical view of the older widow confined to her home; as Katie, her young carer in Act IV, puts it, it is hard to find "many eighty-year-olds that go backpacking around the world" (93). The image of Elsie's mimicking the famous orgasm sequence from the film When Harry Met Sally during the same trip is supposed to create the same effect, or at least it shocked Elsie's own daughter when they visited the emblematic diner in New York (93). Besides revealing the character's sharp 
and often self-parodic sense of humour, the anecdote (like others of a sexual nature in the play) presents Elsie as a sexual being, before and during her fifty-one-year-long marriage, even when her husband's "rubbing and blowing" her hands due to her bad circulation "always led to something else" (97). Through this aspect of her characterization, the piece counteracts the sexist and ageist stereotype of the asexual (older) woman (Liddy 2017, 167-180), and underlines sex, instead, as a natural part of both her own life and the life cycle. Even more than this, the evocation of sexuality throughout the play becomes an expression of Elsie's love for life itself. Apparently in contrast with this, and thanks to her integrated view of the life course, death also becomes an important part of the character's thirst for life. Her direct acquaintance with death throughout her life-ranging from the loss of her mother at a very young age (26), through the hardships of the war (49), to the many other deaths to which, in her seventies, she says do not come as a surprise (66)—does not prevent the character from maintaining the vital disposition that she already shows, as a young woman, at the beginning of the play. As she tells Scarlett in Act III: "When you know a lot of life has been lost so young you embrace every second, you do not wish it to end" (77).

Having considered the dramaturgical elements and aspects of characterization that signify different dimensions of age and ageing in the play, it is worth considering the "age effects," to quote Moore (2014), that the piece can exert on its readers and viewers. In her essay on mainstream British theatre, the age and theatre scholar adapts Butler's notion of 'effect' as a way of understanding identity as culturally-informed $(2006,199)$. Building on this adaptation, we can state that the combination of Elsie's predominantly Naturalistic conception with a highly coherent episodic presentation of her life favours an empathic response towards the character, through which readers and viewers get to feel 'with' her the different changes that life brings. In addition, positive traits of her personality that are sustained throughout the four acts of the play (such as her sense of humour, her caring disposition towards others, her strong sense of friendship, and her loyalty to the community) reinforce the channels of empathy towards the character and, in this way, favour a deeper understanding of what it means to grow older. It is through the mechanism of dramatic irony that this 'empathic age effect' is more effectively attained. This is produced every time one of the young characters ignores a detail of Elsie's life (for example, the fact that she has lost her husband), or goes through a situation that Elsie has had to cope with in previous acts (such as that of being the stranger in a close-knit community). In all those cases, and thanks to the knowledge gained about Elsie's life throughout the play, the reader/viewer is capable of imagining what the main character is feeling for, through, or because of, her younger counterpart. 
These moments of 'empathic revelation' offer, again, invaluable insights about the experience of ageing. Some of them bear an overtly anti-ageist message, especially when Elsie vindicates herself as a person (beyond, despite or even because of her old age). This is clearly the case in Act IV, when Elsie's overprotective carer tends to patronize her, even infantilize her, especially when Elsie looks confused at times. Interestingly enough, Elsie responds to some of those moments of age-based inferiorization with an ambivalent response that empowers her- "I chose not to remember," she tells Katie, when she had briefly forgotten that the community is preparing a birthday party for her (100)—or, even more intensely, and with great comic effect, with an exaggerated performance of her own frailty that ridicules the younger character-by playing with her deafness, she makes Katie repeat three times that she is a fool (98). Through these examples, the play emphasizes on the performative aspects of (old) age and, in this way, dismantles essentialist notions of ageing that disempower or reify the older person, while at the same time recognizing a space of agency in one's re-presentation of old age. Elsie's asking Katie not to "patronise her" towards the end of the last act, when Katie thinks they should get home because the excitement of returning to the village hall is making her too tired (100), signifies even more directly Elsie's vindication of her personhood (and her age).

More than recreating intergenerational tensions, however, the piece reproduces different perceptions of time based on the characters' own age. While to the young Elsie and the other three young characters, time follows the sequential logics of Newtonian time, to the more mature and older Elsies, time becomes an intricate web of experiences, places, people, affections. The "ghosts" that the older Elsie 'sees' in the village halls, and the moments she evokes while re-visiting the space again and again, are the same characters and scenes the audience and readers have seen or come to learn about throughout the play. When she tells Katie that "[p]eople, moments, are clouding up" (92), Hartley seems to evoke, through her perception, the multi-layered, non-linear experience of time that philosophers like Jan Baars associate with ageing (2012). Closely connected with this, and reinforcing the non-confrontational portrayal of intergenerational dialogue that the playwright recreates in the four acts, Elsie offers her own house to Katie at the end of the play; in this way, Katie and her family can continue living in the village and, at the same time, contribute to the community's survival. Elsie's gesture of intergenerational solidarity also becomes a sign of "gerotranscendence," to borrow from Lars Tornstam's term (2005); through it, the older character is capable of imagining (and caring for) life (and the community) beyond her own lifetime. As she tells Katie, who is at first confused by her offer: "I want my home to be a home. I want the person who lives here to have what I did. I want this place to survive. I want the school 
to stay open. Will only happen if you stay." (104) By accepting her own finitude, Elsie replaces a one-directional relationship of care (in which she, as the oldest one, is the one cared for) by one of interdependence, in which the binary carer/ cared for becomes undermined. In a way, at ninety, Elsie is capable of realizing what Elsie at fifty-three already said to her daughter's best friend and protégée, and which is one of the most powerful anti-ageist messages of the play: "People grow up. People grow older. People get weaker. But let them do it on their terms. Marion? On their terms." (55)

\section{Re-Constructing the Ageing Self: Michel Tremblay's Albertine in Five Times}

Revisiting life in search of one's identity and self-forgiveness is the dominant topic of Albertine in Five Times (Albertine, en cinq temps), an award-winning play by Michel Tremblay, one of Canada's most renowned and multifaceted writers. Thirty years after its first production at the Théatre Français of the National Arts Centre in Ottawa in October 1984, it has come to be considered by many as Tremblay's most widely produced and translated play. Like Hartley's piece, Tremblay's text focuses on a seventy-year-old woman, Albertine, who evokes various stages of her life on her first day at a retirement home. However, she does not interact with other characters, but mostly with herself. The playwright indicates that Albertine has "the detached tone of someone returning from far away" (9). It soon becomes clear that she was revived after she had abused some pills. Left 'alone' with her memories, Albertine talks to Madeleine, her long-dead sister and only confidante, and, more significantly, with four younger versions of herself, as she was at the ages of thirty, forty, fifty and sixty. In one of the interviews, Lorraine Pintal, the 2014 production director, states that Albertine in Five Times "is the pinnacle" of all the 'Albertines' found in many of Tremblay's works. ${ }^{2}$ More than three decades after its premiere, this play is still timely and contemporary in its description of women, their struggles for selfhood, fears of loneliness, and, above all, their experience of ageing. In this section, we will examine the ways in which the play's structure and its treatment of space and time are connected with alternative representations of old age. At the same time, we will analyse the author's disruption of the very notion of character, which facilitates alternative depictions of female ageing.

In a way similar to Here I Belong, in Albertine in Five Times we also find a combination of Naturalistic aesthetics (especially reflected in Tremblay's use of

2 See 'Albertine, en cinq temps Returns, 30 Years After its Creation at the NAC,' National Arts Centre https://nac-cna.ca/en/stories/story/albertine-en-cinq-temps-returns-30-years-afterits-creation-at-the-nac 
language and the psychological basis of the character conception) with NonNaturalistic theatrical devices (more evidently manifested in the multiplicity of "selves" into which Albertine is divided, very much reminiscent of a 'Chorus'). This combination reflects the playwright's classical influences, ranging from Greek drama to Samuel Beckett ("Tremblay, Michel"). From the Greeks, the author takes the unity of plot, which can be traced throughout the sequence created by the protagonists' memories; like Beckett, he suspends time and dramatizes the fragmentation of the self. From a structural perspective, Tremblay 'compresses' Albertine's life in a one-act play, in which the action takes place from the sunset to the moonrise, very much like Aristotelian tragedies were supposed to (Aristotle 1989, 11). Nevertheless, this unity is undermined by the portrayal of life images that span forty years. Seen from the perspective of ageing studies, such treatment of time generates its own "age-effects," since it dramatizes ageing as both an interplay and a collage of events, instead of as a linear journey (usually of decline).

When it comes to the play's treatment of space, the piece must also be interpreted in Non-Naturalistic terms, especially because Tremblay divides the dramatic space into five separate locations, from which all Albertines interact. The stage directions inform the reader about the various positions and dramatic spaces that the women concomitantly inhabit, hence establishing the "horizontal" geographies as well as "the "vertical" chronologies of time" in the play (Killick $2011,107)$. Whereas the former are more fixed, and notably bound to social timelines and affairs, the latter are more flexible, and linked to intimate experiences of each character (Killick 2011, 107). Tremblay's multi-layered rendering of time and space generates, to borrow from Lipscomb's words, "a temporal plasticity that foregrounds the social construction of the self" (2016a, 193; italics added), and which highlights the public and private positions (and roles) that Albertine has occupied throughout her life. Indeed, coherent with the precepts of Brechtian or epic theatre, Albertine's life experience is closely connected to various significant historical and socioeconomic life conditions corresponding to twentieth-century Québec (Killick 2011). At the same time, it reflects several historical landmarks, such as the first moon landing and broad access to television. Like Elsie in Here I Belong, Albertine's ageing body is, in Maren Wehrle's words, "lived from within" but "formed from without" (2020, 75; italics in the original). Thus, in Tremblay's play, very much as in Hartley's piece, the process of growing old is linked to "an endless variety of political, economic, social, and cultural contexts" (Kunow 2010, 296), all of which construct, borrowing from Lipscomb's words, "not just a story on stage but an identity" itself (2016b, 7). At the same time, the character's identity can be connected with and re-interpreted through diverse stances and viewpoints. Within its multi-spatial, polivocal dramatization of space (and its 
associated timeframes), Tremblay's portrayal of Albertine's five selves underlines the layered process of identity formation.

The synchronous fragmentation of the main character or the multiplicity of her own self is, however, the main dramaturgical mechanism through which Albertine in Five Times generates its complex representation of ageing. Age scholars like Mangan (2013) and Lipscomb (2016b) have regarded this device as a significant conceit for critical understandings of ageing, since it enables the representation and 're-organization' of identity throughout the life course. Tremblay's main characters in Albertine in Five Times re-organize their life through what Robert Butler called the "life review" or "the progressive return to consciousness of past experiences, and [...] the resurgence of unresolved conflicts" that are commonly associated with the awareness of approaching death $(1963,66)$. Even though the life review may occur at any age, it is commonly associated with the last years of life (Butler 1963, 67, 73). Its implied characteristic is "orderliness" (Butler 1963, 67), but Tremblay's 'dialogic' representation of Albertine's life review is in fact a multi-directional narrative that is generated in both retrospective and forwardlooking ways. His depiction of Albertine's life reflects the complex interaction and interdependency of multiple selves, and at the same time weakens any essentialist idea of identity as 'stable' or even 'fixed.' By unsettling the unity of the ageing character, and depicting it as both estranged from and connected with her younger versions, the playwright exhibits the self as—in the words of Mike Hepworth—"a living process" that evolves throughout the life course (2000, 29). At the same time, and in contrast to the sequential multiplicity of 'Elsies' in Hartley's piece, Tremblay juxtaposes Albertine's fragmented selves against Madeleine's "core self", which expresses, again borrowing from Hepworth's words, a "sense of continuous personal identity" $(2000,29)$. Through this contrast, and more symbolically than Hartley in his duet scenes, Tremblay offers the opportunity to examine what theatre and ageing studies scholars call "an age-old conundrum" of the singularity and plurality of the self (Mangan 2013, 135), or the "paradox of unity and multiplicity" of ageing that are also inherent to the theatre (Lipscomb 2016b, 14).

Albertine's splitting identities also convey social and cultural readings of age. Through its pentagonal characterization, Albertine effectively disrupts the binary division between 'young' and 'old' by creating what Woodward terms "age gradations" $(1991,6)$, that is, the decade-ageing pattern that underlies a continuous progression and interconnectedness between various stages of life. As sociologist Justine Coupland elucidates, within the "cultural time" context, ten-year units are frequently used as measurements by which society prescribes certain beliefs, tenets, manners, and priorities to a particular decade (2009, 960; italics in the original). However, when it comes to "personal time", decades typecast leitmotifs "of bodily appearance, capability, social capital, preferences 
and practices" that, in general terms, empower "the decremental biological model" of ageing (Coupland 2009, 960; italics in the original) and, consequently, pave the way for "the master narrative of decline" (Gullette 2004, 132). Albertine in Five Times and its eponymous quintet is an exemplification of the 'ebb and flow' of the decline narrative that, despite the dramaturgical innovations of the piece, is embodied in the ageing (gendered) character.

The fact that Tremblay presents Albertine in five different ages suggests that the construction of female ageing is socially embraced and culturally exposed within the patriarchal world that marks (older) women as inferior to men. Through Albertine's 'five times' or life stages, Tremblay exemplifies the ways in which the female protagonist internalizes or reacts against her double marginalization as an older woman by either embracing or rejecting various traits of all her former female selves. Abertine is introduced to the reader as a woman of seventy; however, the first self she encounters is her thirty-year-old counterpart. The construction of Albertine's age for the reader starts with young adulthood, just as the first Elsie in Hartley's piece. Seen form the point of view of the young protagonists, this, in Gullette's terms, is "a dangerous age- a tense, threatening, crowded, and overwhelming time" $(1988,6)$. Albertine at 30 perfectly embodies this danger much more than the young Elsie does. A bit fleshy, though very attractive, the young Albertine has escaped to her mother's farmhouse in Duhamel from her arduous and stressful city life, as well as from her suffocating domestic imprisonment as a married woman and a mother, to which she reacts with violence. Hence, the thirty-year-old Albertine entrusts Madeleine with the story of beating her daughter Thérèse, and the scaring inability to manage and control her own anger. The desperation caused by her incapacity to adjust to the traditional woman's roles, and the perplexing feeling of being "in a hole [...], in a tunnel, in a cage" (41), clearly mirror what Betty Friedan labels as the nameless "problem" or "the feminine mystique" (Friedan 2001), and result in loud, yet action-less, outcries caused by her frustrated and enraged femininity. This fury is aggravated by social disdain and her hopelessness within the ageist society in which the young Albertine's predicts a disappointing future: "In ten years, twenty years, we'll still be there, in our cage, behind bars! And when we're old, when nobody needs us anymore, they'll put us in a cage for old ladies! And we'll die of loneliness!" (42)

Tremblay anticipates various 'tragedies' in Albertine's life: one of being a woman in the patriarchal world, and another of being an old woman in an ageist society. The former starts manifesting itself a decade later, when Albertine at 40, "a bit plumper than she was at 30" (11), with hardened features and shabby clothes, speaks from the balcony of her flat on Fabre Street, and confesses that she is stuck in burdensome housewifery and family responsibilities. Consumed with anger against the world she is trapped in, she claims: "I've got no reason to 
cry, just to scream" (71). Deprived of sympathy and love, and now a widow left alone with her problematic children, she claims that it is rage that "keeps [her] alive" (48). At the threshold of middle age, she is torn apart by jealousy towards Madeleine, her guilt for having failed as a mother, and, above all, her regrets for not having reacted against the sense of inferiority that is imposed on her as a woman: "Men are all the same. They always end up on top. What do you expect, they're in charge. We let them have their way and they take advantage of it, they're not stupid! It's their world. They're the ones who made it." (64)

In her often quoted essay The Double Standard of Ageing (1972), the American feminist writer and activist Susan Sontag alerts about the dangers of being a woman in a world that idolizes youth, and renders ageing women invisible, asexual and useless. For this reason, she asserts that disobedience is the way towards freedom (Sontag 1972, 38). The jolly and very thin Albertine at 50 seemingly epitomizes Sontag's stance, as she has found the pleasures of rebellion, disobeying and self-fulfilment. While working at her first and only job as a sandwich-maker at a restaurant in Parc Lafontaine, this Albertine has relieved herself from the constraints of housewifery and family charges, and now enjoys her newly found freedom in her late-middle age. However, her apparent "midlife progress narrative," in Gullette's terms (1988), is not built on solid ground: as her sixty-year-old self virulently reminds her, "[t] hat won't last. [...] Because it's just an act [of] pretending to be a happy, positive person." (48) The paradoxical happiness of fifty-year-old Albertine lies in what Woodward calls "pretense" and "masquerade [of her] self-representation" (1991, 148), since this character lives in an imaginary world where the past is never confronted (45).

Interestingly enough, the most noticeable dissonance within Tremblay's multi-vocal portrayal of ageing occurs between Albertine at 60, who is at the limit of the socially constructed category of old, and Albertine at 70, who has already crossed it. Following her period of disobedience while in her fifties, sixty-year-old Albertine ages into a decade of self-pity, sorrow for the death of her daughter, indifference and distrust towards the whole world, hence complying with the Aristotelian peak-and-decline dramatic structure. For the oldest Albertine, however, old age has become a period for reflection, revelation and self-forgiveness. Her move into the retirement home has cured her "of everything, except [her] memories" (78) which, embodied through the other Albertines, become the expression of her self-knowledge. Thus, it is the seventyyear-old Albertine and not her closer counterpart that represents a vital take on life: in fact, she blames Albertine at 60 for giving up on life or, in Lynne Segal's words, for not "staying alive to life itself" $(2014,4)$. Nevertheless, her life review does not transform her into an archetypical wise woman, immune to mistakes; on the contrary, it allows her to accept the inevitability of human tragedy in 
an ironic way: "What's the point of living? We should have the right to live a second life. But given how we're made ... we'd probably make a mess of it again." (55) Thus, Albertine at 70 knows what her younger selves cannot escape from; but the knowledge she has accrued also foregrounds the inevitability of change in the ageing self, which at the same time saves every Albertine from the finality of the 'tragedies' of each age. Having survived her latest one (the overdose from which she was revived), Albertine embraces her own death with humour: "Anyway, next time I land there, I'll be happy to stay. I sure don't want to spend my old age travelling back and forth like that." (10-11) While death does not happen for her, she welcomes her new home, where she says she feels quite comfortable (9-10). Even though the nursing home is commonly associated with decline and senility (and, in fact, in Here I Belong it represents the form of institutionalized care that Elsie wants to avoid), it does not receive negative connotations in Tremblay's play. As perceived by Albertine at 70, "this is home, from now on," and she appreciates the good organization of the place itself (10). Together with her capacity to adjust to new situations, her ability to laugh at herself becomes her most effective emotional weapon. With it, she fights the declinist comments of her sixty-year-old counterpart, to whom she responds "No, I can't let myself discouraged ... help me!" (43), and, at the same time, she rebels against the ageist stereotypes of the world in which "people made [her] feel so ugly when [she] was growing up [...]" (15).

An important aspect of the play's polyphonic representation of the ageing self, and probably one of its most evident 'age effects,' involves what some scholars term as the "age hierarchy" (Dickerson-Putman and Brown 1998; Gullette 2004, 173-175) that is established among the five Albertines, and which associates old age with knowledge, mentorship and virtue: thus, the older ones counsel the younger ones, anticipate the future to them, and even correct their memories. The older Albertines question the choices the younger selves have made and alert them about the consequences of their decision-making for the next Albertine. "Our fate depends on you", says Albertine at 70 to the youngest self (54). This peculiarity of the choral characterization favours an anti-ageist consciousness. Even though there is notable disagreement between the five Albertines, Tremblay not only portrays the oldest one as braver, wiser and emotionally stronger than their younger versions, but also much more satisfied about her present life. Besides, some of the other Albertines explicitly express their dislike for whom they had been at earlier stages: "I wish I had never been like you!" (28), claims Albertine at 50, complaining about Albertine at 40. In this way, the piece subverts the declinist notion that, as we age, we become nostalgic about the past and about how we were. Beyond these inter-generational, intra-personal conflicts, the final scene indicates a certain reconciliation between all the selves as they contemplate 
the moonrise, suggesting that Albertine, at 70, has finally reached what for Erik Erikson was the stage of "ego-integrity" (1998), that is, one in which all past experiences are finally contemplated and integrated into a complete sense of self.

\section{Conclusion: A Modern Drama of Age(ing)}

Due to their reliance on narrative and the notion of character, dramatic texts remain significant sources whereby theatrical conceptualizations of age and ageing can be examined. Even though their predominantly conventional rules may favour the perpetuation of traditional age ideologies, usually influenced by the narrative of decline (Mangan 2013; Moore 2014), they may also resort to dramaturgical mechanisms that bring about age-centred innovations. As has been shown in this study, Here I Belong and Albertine in Five Times constitute two significant examples of playtexts that recreate alternative narratives of ageing and old age through their structures and processes of characterization, while at the same time illustrating the myriad identities that the ageing self integrates. Despite the three-decade distance that separates the two original scripts, both plays approach the topic of ageing in a similarly complex way.

Albeit in different degrees, in both cases the Naturalistic conception of the character is enriched with an epic or Brechtian presentation of its different faces (and ages), hence recreating the "sense of essential self" (Lipscomb 2016b) that facilitates an emphatic identification and/or understanding of the main figure, while at the same time offering various angles from which to re-interpret it. The protagonists' ever-changing age-identities are largely explained through various sociocultural factors (of which gender is paramount) that condition their life course, and help explain their process of ageing at a 'public' level. At the same time, their capacity to integrate all their life experiences and related ages at an advanced stage of their life (in Albertine's case) and/or to transcend their own finitude (as with Elsie's) offers a more personal and dynamic image of ageing, namely, one in which the present engages with the past and, yet, the future continues to matter.

In both plays, too, the superimposition of sequential plot lines centred on the protagonists' adult years, with the episodic or synchronous representation of fragments of their lives, generates a multi-layered temporality that brings the experience of ageing closer to the audience or readers. The composite or fragmented timeframes of the two plays discussed highlight the "mutable" nature of an ageing self (Lipscomb 2016a, 204) as well as the appreciation of what Segal defines as the "complex layerings of identity" that are produced in old age $(2014$, 4). By offering critical moments of the main characters' lives through episodic or fractal narratives, Tremblay's and Hartley's pieces enable to both 
decode and re-compose the age identities that these figures develop over time. In this sense, their readers and viewers are approached to the sense of 'difference' that is experienced by the older person, and by the older woman in particular.

With regard to the characters' 'gender' difference, it is significant that both Hartley and Tremblay explore the intricacies of ageing through a female character. Despite the different periods in which the two texts have been written, both Albertine in Five Times and Here I Belong respond to the global phenomenon of ageing through a gendered lens. At one level, this choice may be related to the feminization of ageing itself, especially if the predominant demographic trends are considered. However, this coincidence can also be explained in symbolic terms as a choice that expresses more acutely the sense of Otherness for which, as Geraldine Cousin puts it, "[t]heatre is ideally suited," and which is often expressed through "a multiplicity of timescales and places [that] mesh together" $(1996,2)$. Tremblay's overlapping account of female memory, as well as Hartley's re-construction and vindication of an anonymous woman's life, can be considered as "gendered strategies" (Port 2005, 109) with which the character's 'alterity,' manifested through both their age and gender, is expressed.

Closely related to the notion of 'alterity' and the feeling of estrangement associated with it, the theatrical convention of discontinuous acting used in the two plays, whereby one character is performed by various actors (essential in Tremblay's text, and also possible in Hartley's piece whenever four actresses play Elsie), or even the explicit 'performance of age' that Here I Belong may lead to (if, as in the original production, the character ages in front of the audience at the end of every act), enhance the performative (and, therefore, dynamic, transformative and also constructed) dimension of age. Whereas by highlighting the performativity of ageing, Hartley and Tremblay dismantle essentialist views of late youth, midlife, old age, and old old age represented in their plays, by generating 'Other' versions of their main characters (either sequentially or simultaneously) they invite readers and viewers to engage with the characters' own experience of becoming. In many ways, Here I Belong and Albertine in Five Times re-present the particular sense of "uncanniness" with which age scholar Amelia de Falco defines the experience of ageing (2010, xv), as well as the feeling of "estr(age)ment" that Fuchs, playing on the Brechtian alienation device, has detected in theatrical renderings of old age (2014). The composite performing styles implicit in the two plays, which draw from both Naturalistic impersonation and Non-Naturalistic or epic acting, favour a critical, and at the same time empathic, form of reception from which the two ageing characters can be understood throughout their constant changes.

The double decoding involved in the reading of the plays' structures, temporalities and character (dis)continuities is rendered natural by theatrical 
convention. In all the cases, the dramaturgical strategies that Albertine in Five Times and Here I Belong resort to potentially facilitate the development of a more acute age awareness, either through implicit mechanisms of identification, or the appreciation of different age-identities, or both. While Tremblay's multivocal text illustrates how a play can alter social values about female ageing, or, in the words of Howard Barker, witness not only "the reiteration of common knowledge but a dislocation of perceptions" (1993, 29), Hartley's piece dramatizes age as a particular 'place' from which one can perform the self distinctively, and ageing as a journey from strangeness (to the community, but also, symbolically, to the self) to self-acceptance and self-knowledge, where one finally 'belongs.' Together, and beyond their thirty-year-long gap, the two plays recreate the destabilizing, uncanny and, yet, liberating effect of regarding the older person through all the dimensions and factors that conform their multi-layered identity. In so doing, they contribute to paving the way for an anti-ageist society, in which all ages can be represented, in their complexity and gender specificities, on and off the stage.

\section{Works Cited}

\section{Primary Sources:}

HartLey, Matt. 2016. Here I Belong. London: Nick Hern Books.

Tremblay, Michel. 2011. Albertine in Five Times. Translated by Linda Gaboriau. Vancouver: Talonbooks.

\section{Secondary Sources:}

Aristotle. 1989. The Poetics. Aristotle: On Poetry and Style. Translated by G.M.A. Grube. Indianapolis: Hackett.

BAARS, Jan. 2012. Aging and the Art of Living. Baltimore: Johns Hopkins UP.

BARKER, Howard. 1993. Arguments for a Theatre. Manchester and New York: Manchester UP.

Basting, Anne Davis. 1998. The Stages of Age: Performing Age in Contemporary American Culture. Ann Arbor: U of Michigan P. https://doi.org/10.3998/mpub.15441

Bengtson, Vern L. and K. Warner Schaie, eds. 1999. Handbook of Theories of Ageing. New York: Springer.

Bernard, Miriam and Lucy Munro. "Theatre and Ageing." In Twigg and Martin 2015, 61-68.

BirNs, Beverly and Dale F. Hay, eds. 1988. The Different Faces of Motherhood. New York: Springer Science+Business Media. https://doi.org/10.1007/978-1-4899-2109-3 
Bond, John, Sheila Peace, Freya Dittmann-Kohli and Gerben J.Westerhof, eds. 2007. Ageing in Society: European Perspectives on Gerontology. London [etc]: SAGE. https://doi.org/10.4135/9781446278918

Bronk, Katarzyna, ed. 2017. Autumnal Faces: Old Age in British and Irish Dramatic Narratives. Oxford: Peter Lang, 2017. https://doi.org/10.3726/b11491

ButLER, Judith. (1990) 2006. Gender Trouble: Feminism and the Subversion of Identity. Abingdon: Routledge.

—. 1993. Bodies that Matter: On the Discursive Limits of "Sex." New York: Routledge.

ButLer, Robert N. 1963. "The Life Review: An Interpretation of Reminiscence in the Aged.” Psychiatry 26 (1): 65-76. https://doi.org/10.1080/00332747.1963.1102 3339

—. 1969. "Age-ism: Another Form of Bigotry." The Gerontologist 9(4): 243-246. https://doi.org/10.1093/geront/9.4_Part_1.243

—. 2008. The Longevity Revolution: The Benefits and Challenges of Living a Long Life. New York: Public Affairs.

Byrski, Liz. 2014. "Conscientious Objections: Feminism, Fiction and the Phoney War on Ageing." In Whelehan and Gwynne 2014, 14-28. https://doi. org/10.1057/9781137376534_2

Bytheway, Bill. 2011. Unmasking Age: The Significance of Age for Social Research. Bristol: Policy P. https://doi.org/10.2307/j.ctt9qgkqj

Cole, Thomas R., Ruth E. Ray and Robert Kastenbaum, eds. 2010. A Guide to Humanistic Studies in Aging: What Does it Mean to Grow Old? Baltimore, Md.: Johns Hopkins UP.

Coupland, Justine. 2009. "Time, the Body and the Reversibility of Ageing: Commodifying the Decade." Ageing and Society 29 (6): 953-976. https://doi. org/10.1017/S0144686X09008794

Cruikshank, Margaret. 2009. Learning to Be Old: Gender, Culture, and Aging. Plymouth UK: Rowman and Littlefield.

Cousin, Geraldine. 1996. Women in Dramatic Place and Time: Contemporary Female Characters on Stage. London: Routledge.

De Falco, Amelia. 2010. Uncanny Subjects: Aging in Contemporary Narrative. Columbus: The Ohio State UP.

Dickerson-Putman, Jeanette and Judith K. Brown, eds. 1998. Women Among Women: Anthropological Perspectives on Female Age Hierarchies. Urbana and Chicago: U of Illinois P.

Dolan, Josephine and Estella Tincknell, eds. 2012. Aging Femininities. Newcastleupon-Tyne: Cambridge Scholars.

Elias, Norbert. 1985. The Loneliness of the Dying. Translated by Edmund Jephcott. Oxford (UK) and New York: B. Blackwell.

Erikson, Erik H. and Joan Erikson. 1998. The Life Cycle Completed. New York: Norton. 
Friedan, Betty. (1963) 2001. The Feminine Mystique. London and New York: W.W. Norton.

Fuchs, Elinor. 2014. "Estragement: Towards an 'Age Theory' Theatre Criticism." Performance Research. 19 (3): 69-77. http://dx.doi.org/10.1080/13528165.201 4.935177

—. 2016. "Rehearsing Age." Modern Drama, Special Issue: Aging and the Life Course. 59 (2): 143-154. https://doi.org/10.3138/md.59.2.1

GillesPIE, Ben and Bess Rowen. 2020. "Against Chronology: Intergenerational Pedagogic Approaches to Queer Theatre and Performance Histories." Theater Topics 20 (2): 69-83. https://doi.org/10.1353/tt.2020.0030

Goffman, Erving. 1956. The Presentation of Self in Everyday Life. Edinburgh: U of Edinburgh.

Goldman, Marlene and Lawrence Switzky, eds. 2016. Modern Drama, Special Issue: Aging and the Life Course 59 (2). https://doi.org/10.3138/md.59.2.0

GreER, Germaine. 1992. The Change: Women, Ageing and the Menopause. London: Penguin Books.

Hartung, Heike and Roberta Maierhofer, eds. 2009. Narratives of Life: Mediating Age. Wein and Münster: LIT Verlag.

Gullette, Margaret Morganroth. 1988. Save at Last in the Middle Years. Berkeley [etc.]: U of California P.

—. 2004. Aged by Culture. Chicago: U of Chicago P.

-. 2011. Agewise: Fighting the New Ageism in America. Chicago and London: U of Chicago P. https://doi.org/10.7208/chicago/9780226310756.001.0001

—. 2017. Ending Ageism, or How Not to Shoot Old People. New Brunswick: Rutgers UP. https://doi.org/10.2307/j.cttlqlcqsm

Henderson, Julia. 2016. "“I'm an Old Fucking Woman as of Today": Sally Clark's Dramaturgies of Female Aging." Age, Culture, Humanities 3. https:// ageculturehumanities.org/WP/im-an-old-fucking-woman-as-of-today-sallyclarks-dramaturgies-of-female-aging/

HePworth, Mike. 2000. Stories of Ageing. Buckingham and Philadelphia: Open UP. Katz, Stephen. 2005. Cultural Aging: Life Course, Lifestyle, and Senior Worlds. Peterborough: Broadview P. https://doi.org/10.3138/9781442602083

-. 2014. "What Is Age Studies?" Age, Culture, Humanities 1: 17-23. https:// ageculturehumanities.org/WP/what-is-age-studies/

KenYon, Gary M., Jan-Eric Ruth and Wilhelm Mader. 1999. "Elements of a Narrative Gerontology." In Bengtson and Schaie 1999, 40-58. 
Killick, Rachel. 2011. "“Out of Time”: Memory and Mortality, Self and Society in Michel Tremblay's Albertine, en cinc temps.” Québec Studies. 51 (1): 107-120. https://doi.org/10.3828/qs.51.1.107

KING, Jeannette. 2013. Discourses of Ageing in Fiction and Feminism: The Invisible Woman.

Basingstoke: Palgrave Macmillan. https://doi.org/10.1057/9781137292278

KuChNER, Joan F. and Jane Porcino. 1988. "Delayed Motherhood." In Birns and Hay 1988, 259-280. https://doi.org/10.1007/978-1-4899-2109-3_12

Kunow, Rüdiger. 2010. "Old Age and Globalization." In Cole, Ray and Kastenbaum 2010, 293-318.

LidDY, Susan. 2017. "Older Women and Sexuality On-Screen: Euphemism and Evasion?” In McGlynn, O’Neil and Schrage-Früh 2017, 167-180.

https://doi.org/10.1007/978-3-319-63609-2_10

Lipscomb, Valerie Barnes. 2012. "”The play's the thing”: Theatre as a Scholarly Meeting Ground in Age Studies." International Journal of Ageing and Later Life 7 (2), 117-141. https://doi.org/10.3384/ijal.1652-8670.1272a6

—. 2016a. "Age in M. Butterfly: Unquestioned Performance." Modern Drama, Special Issue: Aging and the Life Course 59 (2): 193-212. https://doi.org/10.3138/ md.59.2.4

—. 2016b. Performing Age in Modern Drama. New York: Palgrave Macmillan. https:// doi.org/10.1057/978-1-137-50169-1

Lipscomb, Valerie Barnes and Leni Marshall. 2010. Staging Age: the Performance of Age in Theatre, Dance, and Film. New York: Palgrave Macmillan.

Macdonald, Barbara and Cynthia Rich. (1983) 2001. Look Me in the Eye: Old Women, Aging and Ageism. Denver: Spinsters.

Mangan, Michael. 2013. Staging Ageing: Theatre, Performance, and the Narrative of Decline. Bristol, UK and Chicago: Intellect.

McCormick, Sheila. 2017. Applied Theatre: Creative Ageing. London: Methuen. https://doi.org/10.5040/9781474233866

McGlynn, Cathy, Margaret O’Neill and Michaela Schrage-Früh, eds. 2017. Aging Women in Literature and Popular Culture: Reflections, Reflactions, Reimaginings. Cham: Palgrave Macmillan. https://doi.org/10.1007/978-3-319-63609-2

Moore, Bridie. 2014. "Depth, Significance, and Absence: Age-Effects in New British Theatre." Age, Culture, Humanities 1: 163-195. https://ageculturehumanities. org/WP/depth-significance-and-absence-age-effects-in-new-british-theatre/

—. 2018. "Effects, Metaphors, and Masks: Reading and Doing Age in Contemporary British Theatre." PhD diss., University of Sheffield.

Peace, Sheila, Freya Dittmann-Kohli, Gerben J. Westerhof and John Bond. 2007. “The Ageing World." In Bond, Peace, Dittmann-Kohli and Westerhof 2007, 1-14. https://doi.org/10.4135/9781446278918.n1 
PORT, Cynthia. 2005. “"Money, for the Night Is Coming”: Gendered Economies of Aging in the Early Novels of Jean Rhys.” In Worsfold 2005, 99-115.

Randall, William R. and A. Elizabeth McKim. 2008. Reading Our Lives: The Poetics of Growing Old. Oxford [etc.]: Oxford UP. https://doi.org/10.1093/ acprof:oso/9780195306873.001.0001

Schweda, Mark, Michael Coors and Claudia Bozzaro, eds. 2020. Aging and Human Nature: Perspectives from Philosophical, Theological, and Historical Anthropology. Cham: Springer Nature. https://doi.org/10.1007/978-3-030-25097-3

SEGAL, Lynne. 2014. Out of Time: The Pleasures and Perils of Ageing. London and New York: Verso.

SontAG, Susan. 1972. "The Double Standard of Aging". The Saturday Review 23: 2938.

Swinnen, Aagje, and Cynthia Port. 2012. "Aging, Narrative, and Performance: Essays from the Humanities". International Journal of Ageing and Later Life 7 (2): 9-15. https://doi.org/10.3384/ijal.1652-8670.1272al

Tornstam, Lars. 2005 Gerotranscendence: A Developmental Theory of Positive Aging. New York: Springer.

"Tremblay, Michel." 2021. ENCYCLOPEDIA.COM. www.encyclopedia.com/arts/ encyclopedias-almanacs-transcripts-and-maps/tremblay-michel [Accessed online on February 2, 2021]

TwIGG, Julia and Wendy Martin, eds. 2015. Routledge Handbook of Cultural Gerontology. London and New York: Routledge. https://doi.org/10.4324/9780203097090

Wehrle, Maren. 2020. "Becoming Old. The Gendered Body and the Experience of Aging." In Schweda, Coors and Bozzaro 2020, 75-96. https://doi. org/10.1007/978-3-030-25097-3_6

Whelehan, Imelda and Joel Gwynne, eds. 2014. Ageing, Popular Culture and Contemporary Feminism: Harleys and Hormones. Houndmills [etc]: Palgrave Macmillan. https://doi.org/10.1057/9781137376534

WoODWARD, Kathleen. 1991. Aging and Its Discontents: Freud and Other Fictions. Bloomington and Indianapolis: Indiana UP.

—. 2006. "Performing Age, Performing Gender." NWSA Journal 18 (1): 162-189. https://www.jstor.org/stable/4317191

Worsfold, Brian J., ed. 2005. Women Ageing Through Literature and Experience. Lleida: Edicions i Publicacions de la Universitat de Lleida.

-. 2011. Acculturating Age: Approaches to Cultural Gerontology. Lleida: Edicions i Publicacions de la Universitat de Lleida. 